This is the post print version of the article, which has been published in Archives of Women's Mental ${ }_{1}$ Health . 2018, 21 (3), 323-331. http://dx.doi.org/10.1007/s00737-017-0797-7 .

\title{
RISK FACTORS FOR UNPLANNED PREGNANCY IN WOMEN WITH MENTAL ILLNESS LIVING
}

IN A DEVELOPING COUNTRY

Elsa du Toit ${ }^{1,2}$, Esme Jordaan ${ }^{3}$, Liezl Koen ${ }^{1}$, Jukka Leppanen ${ }^{4}$, Dana Niehaus ${ }^{1}$

${ }^{1}$ Maternal Mental Health Clinic, Stikland Hospital/Department of Psychiatry, Faculty of Health

Sciences, Stellenbosch University, Tygerberg, Cape Town, South Africa

${ }^{2}$ Sophia Maternal Mental Health Care, Panorama Psychiatric Centre

${ }^{3}$ Biostatistics Unit, Medical Research Council, Bellville and the Statistics and Population Studies

Department, University of the Western Cape, South Africa

${ }_{4}^{4}$ Tampere Center for Child Health Research, University of Tampere School of Medicine, Finland 


\begin{abstract}
Pregnant women in general are at an increased risk of experiencing symptoms of mental illness, and those living in a developing country are even more vulnerable. Research points towards a causal relationship between unplanned pregnancy and perinatal mental illness and suggests that pregnancy planning can aid in reducing the negative impact of mental illness on a woman, her unborn baby, and the rest of the family. In this quantitative, descriptive study, we investigated both socio-demographic factors and variables relating to mental illness itself that may place women at an increased risk of experiencing unplanned pregnancy. Data were gathered at two maternal mental health clinics in Cape Town by means of semi-structured interviews. Univariate analyses of the data revealed five independent key risk factors for unplanned pregnancy: lower levels of education, unmarried status, belonging to the Colored ${ }^{1}$ ethnic population, substance use, and having a history of two or more suicide attempts. Some of these factors overlap with findings of similar studies, but others are unique to the specific population (women with mental illness within a developing country). Screening of women based on these risk predictors may pave the way for early interventions and reduce the incidence of unplanned pregnancy and the negative consequences thereof in the South African population.
\end{abstract}

\footnotetext{
${ }^{1}$ In South Africa, the term "Colored" has no derogatory connotation and is used to refer to a group of people from mixed racial heritage - an important and culturally unique segment of the population, mainly based in the Western Cape.
} 


\section{Keywords}

South Africa, unplanned pregnancy, mental illness

\section{Introduction}

In the past, pregnancy was often regarded as a protective factor against the symptoms of mental illness, but it is now recognized as a time during which women are especially prone to an increase in such symptoms (Chisolm \& Payne 2016). Mental illness during pregnancy is associated with poor obstetric outcomes, increased rates of substance abuse, decreased use of antenatal services and increased occurrence of postpartum psychiatric symptoms. As pointed out by both Campion, Bhui \& Bhugra (2012) and Akdeniz (2010), these adverse outcomes, in turn, have a negative impact on the infant and the family as a whole. It is therefore of great concern that symptoms of mental illness are often not recognized during the perinatal period and that treatment rates are lower in pregnant females than in non-pregnant females (Rochat, Tomlinson, Bärnighausen, Newell \& Stein 2011). Campion et al. (2012) strongly advocate early intervention to prevent mental illness as the most effective means of reducing the disease burden.

Research further demonstrates that women in low and middle-income countries have a much higher risk of developing antenatal and postpartum depression than women living in high income countries. The prevalence of postpartum depression in South Africa is estimated at almost 40\% (Rochat et al. 2011), compared with between $4.7 \%$ and $13 \%$ in Great Brittain (Khalifeh, Brauer, Toulmin \& Howard 2015) and between $8.3 \%$ and 12.7\% in the United States (Grote et al. 2010). Currently, perinatal mental health service delivery in South Africa is highly variable, with many areas offering little or no support to women with mental illness during the perinatal period. According to Paschetta et al. (2014), less than $8 \%$ of women with diagnosable mental illnesses who live in developing countries receive any treatment for their mental illness during the perinatal period. Similarly, Honikman et al. (2012) reported that although $92 \%$ of the South African pregnant population receive some antenatal care, such care is mainly focused on physical examination with a lack of screening or treatment for maternal mental disorders.

According to Paschetta et al. (2014) pregnancy planning can help to reduce the negative impact of mental illness on a woman, her unborn baby, and the rest of the family by providing the opportunity to discuss 
treatment and finalize a management plan prior to the pregnancy. Unplanned pregnancies (comprising those that are unintended, mistimed and unwanted) are common, accounting for between $30 \%$ and $50 \%$ of pregnancies globally (Helfferich, Hessling, Klindworth \& Wlosnewski 2014). Not only is unplanned pregnancy one of the main predictors of inadequate use of prenatal services (Delgado-Rodríguez, Gómez-Olmedo, BuenoCavanillas \& Gálvez-Vargas 1997), but there is also a significant relationship between pregnancy planning and other prenatal health behaviors (Özkan \& Mete 2010). According to these studies, women with unplanned pregnancies smoked more, took fewer vitamins, and waited longer before seeking prenatal care. Haddad, Makin, Pattinson and Forsyth (2016) cite that in South Africa more than half of pregnant women only present at prenatal clinics after 20 weeks' gestation. They found, however, that women with planned pregnancies are significantly more likely to seek prenatal care early. In addition, women with unplanned pregnancies reported more medical problems during their pregnancies than those with planned pregnancies.

The negative impact of unplanned pregnancy on maternal and fetal health is indeed very similar to the negative outcomes experienced by pregnant women with untreated mental illnesses. In fact, unplanned pregnancies are also associated with an increased rate of perinatal maternal depression (Abajobir, Maravilla, Alati \& Najman 2016). Abajobir et al. (2016) point out that maternal mental health problems have been cited as both a cause and a consequence of unintended pregnancies by various researchers.

This study does not aim to look at the causality between mental illness and unplanned pregnancy, but rather at factors associated with an unplanned pregnancy for women in a developing country living with a serious mental illness (DSM-IV-TR axis 1 (APA 2000) diagnosis). Both socio-demographic factors and factors relating to the mental illness itself will be taken into account. Gelaye et al. (2016) point out the importance of integrated prenatal care programs specifically aimed at identifying and treating perinatal mental health problems in low- and middle-income countries, as for many women living in such countries the prenatal period is a first and often only time of contact with the healthcare system. According to the Prenatal Taskforce of the Western Cape (2016), maternal mental health is not currently being prioritized in this province and basic antenatal care tools contain limited maternal mental health and psychosocial assessment tools. The taskforce suggests a more comprehensive care package, including psycho-social risk screening and more comprehensive education and information during antenatal care. However, if such screening and education could be made available before the antenatal period, it might aid in reducing the prevalence of unplanned pregnancy. This study aims to contribute towards making such an integrated and comprehensive approach possible by identifying factors that may render women diagnosed with mental illness (within a developing country) at 
greater risk for unplanned pregnancy. Other role players, such as policy makers, educators, social workers, and primary healthcare providers, need to be made aware of the risk factors for unplanned pregnancy in this group of vulnerable women in order to facilitate targeted screening and prevention programs and early referrals to specialized health care professionals. Possible risk factors taken into account include socio-demographic variables (based on the findings of Özkan and Mete (2010) in a Turkish population), factors relating to previous pregnancies, and variables relating to the mental illness itself.

\section{Materials and methods}

\section{Study design:}

This quantitative, descriptive study was approved by the research ethics committee of the University of Stellenbosch, and permission was granted by Stikland Hospital and the Provincial Government of the Western Cape. The study described in this article covers one aspect of a larger ongoing follow-up study that will assess the naturalistic outcomes of pregnancies in females with a DSM-IV-TR axis 1 diagnosis of psychiatric illness (APA 2000). Participants are studied from conception (or their first presentation at one of the recruitment sites) until 6 weeks postpartum with the aim of assessing pregnancy outcomes in a real-world setting. Other aspects of the larger study include genetic sampling and infant outcomes for mothers with mental illness.

\section{Setting:}

The study was conducted at two Maternal Mental Health Clinics in Cape Town, South Africa: Stikland Maternal Mental Health Outpatient Clinic and Sophia Perinatal Psychiatry Centre. Both these clinics offer perinatal mental health care on an outpatient basis, but the former is part of a state-owned psychiatric hospital, whereas the latter is privately-owned. Patients at both clinics are usually referred by primary health care providers, but in the case of the private facility patients may also self-refer. Currently, there is a substantial difference in cost between private and public medical care in South Africa, with public care being more affordable and the only option available to the majority of South Africans. Private medical care is expensive in relation to the wealth of the country, with prices on par with that of first world countries such as Germany and France (Lorenzoni \& Roubal 2016). The participants recruited from the private clinic have a higher average income than those recruited at the state clinic and they must either have access to medical aid or the financial means to afford private medical tariffs. Study participants were recruited in a ratio of 3:2, with the majority hailing from the state clinic. Although $83 \%$ of South Africans are dependent on state-provided medical care 
(Lorenzoni \& Roubal 2016), the recruitment ratio does give a realistic picture of the current utilization pattern of more specialized medical services, such as high risk maternal mental health care. The state-provided service is mainly focused on primary health-care provision, with less referrals for specialized treatment than in the private care context.

\section{Participants:}

All 214 participants were pregnant female mental health patients referred to the aforementioned clinics by general practitioners, gynecologists, psychiatric or obstetric nurses due to known psychiatric illness or for assessment and management of new psychiatric symptoms - 130 participants were recruited from the state clinic and 84 from the private clinic. Pregnant females 18 years and older with a primary DSM-IV-TR (APA 2000) diagnosis of psychiatric illness qualified for inclusion in the study. Both women with previously diagnosed psychiatric illnesses and women diagnosed upon presentation at one of the recruitment sites were included in the study.

Participants entered the research program on a voluntary basis. Interviews were conducted in English and Afrikaans, with translators assisting in cases where participants were unable to converse in either of these languages (e.g. women speaking one of the 9 other official languages who relocated to Cape Town from rural areas). In order to be included in the study, participants had to give written, informed consent. Those who were unable to give informed consent or refused to do so were excluded from the study. The standard care of women was not influenced by their participation or non-participation in the program.

\section{Data collection:}

Data were collected between April 2011 and May 2016 during care-as-usual visits at the aforementioned clinics. Although data-collection is an ongoing process, only women seen in this period were included in our cohort.

Upon presentation at one of the recruitment sites, study participants completed an initial semi-structured interview, including a thorough psychiatric assessment (as per care-as-usual). All interviews were between 60 and 90 minutes in duration and were conducted by either a qualified psychiatrist with a minimum of 5 years' experience or a psychiatric registrar under supervision of such a psychiatrist. A questionnaire including both open- and closed-ended questions was constructed by the researcher and used as guide for the interviewer and 
for the recording of information. The information was later extracted onto the data capturing platform by a dedicated data capturer, using a pre-selected coding system.

During these initial interviews, the following information was obtained: socio-demographic background (maternal age, self-reported ethnicity, level of education, employment status, and marital status), current mental state, current physical health (including an assessment of co-morbid conditions), obstetric, psychiatric and general medical history, a list of medication used currently and in the past, substance use habits (if any), and a brief family history of mental illness.

Pregnancy intent was assessed by means of two questions: firstly, 'Is this a planned pregnancy?' and secondly, 'Do you want the baby?'.

In each case a psychiatric diagnosis was made according to the diagnostic criteria set out in the Diagnostic and Statistical Manual of Mental Disorders (DSM IV - TR). Table 1 provides a summary of psychiatric diagnoses within the study sample. The majority of the study participants had an Axis I diagnosis (primary or comorbid) of major depressive disorder (54\%). This was followed by diagnoses of anxiety disorders (23\%), bipolar disorder (type I or II) (22\%), and schizophrenia spectrum disorders (17\%). The remaining $2 \%$ had other diagnoses, including adjustment disorders and eating disorders.

Study participants were followed up once during each consecutive trimester and again at week six postpartum. For most participants, this translated to a total of four visits, but since women presented for their initial visit at different gestational stages, some participants were seen fewer times. However, for the current study, only data from the initial interview was used.

The collection of the research data did not interfere with the standard care of the study participants in any way and psychiatric treatment was not determined by the research interviews, but by collaboration between the patient and her clinician.

\section{Statistical methods}

The outcome for the analysis was the women's responses to the question 'Is this a planned pregnancy?', thus a binary response with a "no" answer indicating an unplanned pregnancy. Risk factor variables collected at the initial interview were described using frequencies and percentages. Because of the cross-sectional nature of the 
data, a Log-Binomial model was used to assess the associations between the outcome of interest and the risk factors. The measure of risk was the risk ratio with $95 \%$ confidence intervals, and p values were also provided. Univariate models were conducted first and the multiple regression model assessed the independent risk factors for unplanned pregnancy.

\section{Results}

Table 1 shows the socio-demographic constitution of the study sample. Of the 214 participants, $47.2 \%$ presented with unplanned pregnancies. Women who took part in the study were between the ages of 18 and 46 years, with an average age of 31 years $(\mathrm{SD}=5.7$ years $)$.

At the time of the initial interview $55 \%$ of the women were married and $60 \%$ already had children. The socioeconomic backgrounds of the study participants varied in terms of level of education and employment status. A third of the women had tertiary education, while $57 \%$ had at least secondary education (Gr 8-12). The remaining $8 \%$ only attended primary school. More than half of the women $(55 \%)$ were unemployed, either out of choice or because they were unable to find employment or still studying.

Women presented for their initial interviews at different stages of their pregnancies (ranging from 4 weeks' gestation to 38 weeks' gestation), with nearly 3 out of 5 women presenting after 12 weeks' gestation. The mean gestational age at the initial presentation was 16.9 weeks $(\mathrm{SD}=9.3)$ and the median 15 weeks.

For $27 \%$ of women this was their first pregnancy, while $23 \%$ had 4 or more previous pregnancies. At least one previous termination of pregnancy was reported by $15 \%$ of study participants.

\section{$\underline{\text { Risk factors associated with unplanned pregnancy }}$}

Results for the univariate regression models are provided in Table 2 and for the multiple regression models in Table 3.

\section{Maternal and pregnancy factors}

Younger women were significantly more likely to report an unplanned pregnancy than older women - this holds true when looking at the ages of the women in their current pregnancies $(<35 \mathrm{yrs}[52.7 \%]$ vs $>=35 \mathrm{yrs}$ 
[34.9\%], $\mathrm{p}=0.027$ ). Women who have been pregnant more than twice in the past, showed a significant but marginal increase in likelihood for current unplanned pregnancy, compared to those who have been pregnant two or less times $(\mathrm{RR}=1.4, \mathrm{p}=0.025)$. Women who reported previous terminations of pregnancies did not show an increased likelihood of unplanned pregnancy compared to those who had no previous terminations $(\mathrm{p}=0.147)$

Socio-demographic factors and ethnicity

The drainage areas of the recruitment sites include predominantly suburbs with high percentages of Colored and Caucasian residents. Due to the resulting low number of African and Indian participants, these races were grouped together for data analysis purposes. Colored (C) and African/Indian (A) women revealed a higher likelihood for current unplanned pregnancy than Caucasian women $(C: R R=4.3$ and $A: R R=2.9)$. Unmarried women were more likely to present with unplanned pregnancy than married women $(\mathrm{RR}=2.9)$. Women with no tertiary education showed a higher likelihood for unplanned pregnancy compared to those with tertiary education (secondary education: $\mathrm{RR}=5.7$ and primary education: $\mathrm{RR}=7.3$ ). Unemployment was associated with an increased likelihood for unplanned pregnancy $(R R=2.4)$, and so was an income lower than ZAR 4166 per month (about $\$ 300$; this is the lowest income stratum according to the government classification system and state medical services are largely subsidized by the government for this group) $(\mathrm{R} R=1.6)$.

\section{Factors related to psychiatric history}

Women who reported substance use (any alcohol or illicit drug use, including amphetamine or cannabis) showed a higher likelihood for an unplanned pregnancy than that of non-users $(R R=1.8)$. Furthermore, women with a history of suicide attempt(s) revealed a higher likelihood of an unplanned pregnancy than those who have never attempted suicide ( 1 attempt: $R R=1.5$ or more suicide attempts: $R R=2.1$ ). Women who reported previous psychiatric admissions were more likely to have unplanned pregnancies than those with no previous admissions $(\mathrm{RR}=1.8)$. Due to the small size of the sample, associations between different psychiatric diagnoses and unplanned pregnancy was not considered in this study.

\section{Independent risk factors for an unplanned pregnancy (See Table 3)}

The multiple regression model indicated five independent risk factors to be associated with current unplanned pregnancy. According to the model, Colored women have a significantly higher risk than Caucasian women $(R R=2.1, p=0.004)$, unmarried women have a higher risk than married women $(R R=1.4)$, women with less than 
tertiary education have an increased risk (secondary education: $R R=3.2$ and primary education: $R R=3.7$ ), and so do women with a history of two or more suicide attempts $(R R=1.4)$. Women who reported substance used also have an increased risk $(\mathrm{RR}=1.27)$

\section{Discussion}

Almost half of our sample (47.2\%) reported that they did not plan the current pregnancy. The high rate of unplanned pregnancy is not surprising, as a study investigating substance use in pregnant mothers attending Midwife Obstetric Units in Cape Town $(n=684)$ reported an unplanned pregnancy rate of $68.2 \%$ among women attending said units (Williams et al. 2014). The high rate of unplanned pregnancy in a sample of mothers with psychiatric illness is concerning, as they are particularly vulnerable to relapse of their illness during the perinatal period. The identification of factors that predict unplanned pregnancy in this group is therefore very important as it may be a first step towards informing mental and obstetric health policy - once risk factors have been established, a motivated appeal can be made for policy changes, including targeted prevention and screening programs.

Our results suggest that for women with mental illness living in South Africa, the presence of one or more of the following factors may increase the risk of unplanned pregnancy: being younger, having been pregnant two or more times in the past, Colored, African or Indian ethnicity, unmarried status, below tertiary education level, unemployed status, low income level, substance abuse habits, previous psychiatric admissions, and a history of attempted suicide(s).

Although our study sample did not include a control group without psychiatric illness, existing literature suggests that many of the above-mentioned risk factors also apply to women without mental illness, including ethnicity (Hodgson et al., 2013), unmarried status, lower education levels, and substance use (Wellings et al., 2013). Other factors, such as psychiatric admissions, and attempted suicide(s) are however related to the psychiatric diagnosis and may suggest that severity of mental illness could play a compounding role in the prevalence of unplanned pregnancy - a possibility that may be further explored once more data becomes available. Where a risk-factor related to a woman's psychiatric illness coincide with other risk factors, she may be particularly susceptible to unplanned pregnancy. Furthermore, where mental illness forms part of the picture and unplanned pregnancy does occur, women (and their offspring) are particularly vulnerable to the adverse 
consequences of unplanned pregnancy mentioned in the introduction, such as delayed and inadequate use of perinatal services, increased smoking, and failure to use recommended nutritional supplements.

Possible interplay among the identified risk factors may give rise to a discussion about the direction of causality. Determining which of the risk factors give rise to the others and which ones serve to perpetuate others, requires a very complex study in itself. For the purpose of the current study, it is however important to note that interrelationships among the various risk factors do exist. For example, most of the socio-economic factors found to be related to unplanned pregnancy are also predictors of alcohol and drug use (Frisher et al., 2007). It is therefore possible that substance use could be a mediating factor for unplanned pregnancy in this study. To investigate this possibility a path analysis, indicating possible direct and indirect paths between the socio-economic indicators and unplanned pregnancy may be done when more data is available.

Similarly, Colored ethnicity, is linked to a specific socio-political framework associated with adverse socioeconomic circumstances such as lower levels of education (Salisbury, 2015), lower family income (Salisbury, 2015), high levels of unemployment (Kingdon \& Knight, 2004), and high prevalence of substance use (Lesch \& Adams, 2016), all of which were also identified as risk-factors for unplanned pregnancy within our subpopulation.

Shisana et al. (2014) found a higher prevalence of risky sexual behavior among unmarried women than married women, explaining unmarried status as a risk factor for unplanned pregnancy in our study. Being younger, which has also been shown to be a risk factor, may, in turn, increase the likelihood of unmarried status. Similarly, a higher level of education is likely to lead to a better chance of employment and a higher income, while, on the other hand, a low family income may be a hindrance to further education.

Socio-economic difficulties are often perpetuated in a vicious cycle and may take a long time to eradicate. Unplanned pregnancy, like mental illness, may in itself become a contributing factor to such a cycle, as it can increase the financial burden on a community, while decreasing opportunities for further education and employment. It is therefore imperative that steps be taken to prevent unplanned pregnancy among vulnerable women, starting with raising awareness about risk factors and implementing targeted screening programs.

Concerning psychiatric risk-factors, an interesting question that arises is why multiple previous suicide attempts places the individual at higher risk for an unplanned pregnancy? Literature suggests an association 
between increased impulsivity and suicide attempts (Wang et al., 2017). The increased impulsivity may also play a role in the sexual behavior linked to unplanned pregnancy. Thus, the severity of illness at the time of conception may render the individual more vulnerable to both suicide attempts and unplanned pregnancy. Some evidence (albeit by proxy) for this possibility may be the finding that in a sample of Xhosa individuals with schizophrenia or schizoaffective disorder, the presence of lifetime bizarre behavior (OR 1.5; 95\% CI 1.12-1.87) increased the risk for suicide attempts (Lückhoff, Koen, Jordaan \& Niehaus 2014).

Although extensive research has been done on the causes and effects of planned versus unplanned pregnancy, literature in this regard pertaining specifically to women with mental illness and living within a developing country, is sparse. Both women with mental illness and those who experience unplanned pregnancy are at greater risk of experiencing adverse pregnancy outcomes and when these two factors exist in combination it deems a woman particularly vulnerable. An understanding of the variables that might lead to such an unfavorable situation can enable healthcare professionals and policy-makers to address the root(s) of a problem that has far-reaching consequences as future generations are impacted by the health and choices of a mother during the perinatal period. This research is especially important in a developing country like South Africa, where the provision of specialized medical services, such as perinatal mental health services, are often least available to those who need it most (those with adverse socio-demographic situations).

One limitation of this study is the use of two closed-ended oral questions to determine intent of pregnancy. These could potentially be misinterpreted and do not necessarily allow for the subtleties of feeling that a woman may experience around her pregnancy. This is highlighted by the fact that $62 \%$ of women with unplanned pregnancies said, upon initial interview, that they wanted the baby, while $33 \%$ of these women indicated that they did not want the baby (the remaining 5\% felt ambivalent). A more nuanced tool for determining pregnancy intent, such as the London Measure of Planned Pregnancy (Barrett, Smith \& Wellings, 2004), may yield more accurate results.

Another limitation inherent to the study design, is the fact that women with unplanned pregnancies may have early miscarriages or choose to terminate their pregnancies before the opportunity for referral to a maternal mental health clinic arises, which would automatically exclude them from the study sample. It follows that the incidence of unplanned pregnancy among women with mental illness could potentially be somewhat higher than the $47 \%$ indicated by our sample. A study looking at the incidence of mental illness in women who choose to terminate pregnancy could provide valuable data in this regard. 
A third limitation is the fact that the study sample is not representative of the greater population of South Africa or the Western Cape in terms of racial constitution and socio-economic background, due to the limited availability of specialized medical services to the majority of South Africans. It is however precisely this inequality of service provision that necessitates studies highlighting the importance of such specialized services to those whose circumstances place them at the greatest need thereof.

It is furthermore important to note that these are provisional results from a study where the recruitment is ongoing - statistical findings may evolve with an increase in the size of the study population.

\section{Conclusion}

Socio-demographic factors that were found to elevate the risk of unplanned pregnancy for women with mental illness within a South African context included low level of education, substance abuse, unmarried status, previous pregnancies, and belonging to the Colored population. Factors related to mental illness that translated into an increased risk, included having attempted suicide two or more times and previous psychiatric admissions. Screening of women based on these risk predictors prior to pregnancy, as part of an integrated and comprehensive healthcare program, may enable healthcare workers and policy-makers to stage early interventions and reduce the incidence of unplanned pregnancy and the negative consequences thereof in the South African population. Pregnancy planning education during early teenage years as part of the national education program may aid in preventing teenage pregnancies and breaking a pattern where girls tend to fall pregnant at a young age and cease their education, thus putting them at risk for further unplanned pregnancies. Active measures also need to be taken to make it possible for girls with teenage pregnancies to return to school (e.g. provision for childcare). Preventive screening and pregnancy planning education of all reproductive women presenting at health care services may aid in reducing the occurrence of unplanned pregnancies. However, screening of pregnant women for mental health risks is equally important to prevent adverse outcomes in current pregnancy as well as subsequent unplanned pregnancies. 


\section{References}

1. American Psychiatric Association (2000) Diagnostic and statistical manual of mental disorders (4th ed. text rev.). Washington DC: American Psychiatric Publishing

2. Abajobir AA, Maravilla JC, Alati R, Najman JM (2016) A systematic review and meta-analysis of the association between unintended pregnancy and perinatal depression. J Affect Disord 192:56-63. doi: 10.1016/j.jad.2015.12.008

3. Akdeniz F (2010) Female-specific problems in mental patients. Curr Opin Psychiatry 23(4):378-382. doi:10.1097/YCO.0b013e32833ae437

4. Barrett G, Smith SC, Wellings K (2004) Conceptualisation, development, and evaluation of a measure of unplanned pregnancy. J Epidemiol Community Health 58(5):426-433. doi:

5. Campion J, Bhui K, Bhugra D (2012) European Psychiatric Association (EPA) guidance on prevention of mental disorders. European Psychiatry 27(2):68-80. doi:10.1016/j.eurpsy.2011.10.004

6. Chisolm MS, Payne JL (2016) Management of psychotropic drugs during pregnancy. BMJ 352:h5918 doi:10.1136/bmj.h5918

7. Delgado-Rodríguez M, Gómez-Olmedo M, Bueno-Cavanillas A, Gálvez-Vargas R (1997) Unplanned Pregnancy as a Major Determinant in Inadequate Use of Prenatal Care. Preventive Medicine 26:834-838.

8. Frisher M, Crome I, Macleod J, Bloor R, Hickman M (2007) Predictive factors for illicit drug use among young people: a literature review. Report produced by the Research Development and Statistics Directorate, UK Home Office. Retrieved from http://dera.ioe.ac.uk/6903/1/rdsolr0507.pdf on $23 / 01 / 2017$. 
9. Gelaye B, Rondon MB, Araya R, Williams MA (2016) Epidemiology of maternal depression, risk factors, and child outcomes in low-income and middle-income countries. The Lancet 3(10):973-982. doi:10.1016/S2215-0366(16)30284-X

10. Grote NK, Bridge JA, Gavin AR, Melville JL, Iyengar S, Katon WJ (2010) A Meta-analysis of Depression During Pregnancy and the Risk of Preterm Birth, Low Birth Weight, and Intrauterine Growth Restriction. Arch Gen Psychiatry 67(10):1012-1024. doi:10.1001/archgenpsychiatry.2010.111

11. Haddad DN, Makin JD, Pattinson RC, Forsyth BW (2016) Barriers to early prenatal care in South Africa. International Journal of Gynaecology and Obstetrics 132(1):64-67. doi:10.1016/j.ijgo. 2015.06 .041

12. Helfferich C, Hessling A, Klindworth H, Wlosnewski I (2014) Unintended pregnancy in the lifecourse perspective. Advances in Life Course Research 21:74-86. doi:10.1016/j.alcr.2014.04.002

13. Hodgson EJ, Collier C, Hayes L, Curry LA, Fraenkel L (2013) Family planning and contraceptive decision-making by economically disadvantaged, African-American women. Contraception 88:289-296. doi:10.1016/j.contraception.2012.10.011

14. Honikman S, Van Heyningen T, Field S, Baron E, Tomlinson M (2012) Stepped Care for Maternal Mental Health: A Case Study of the Perinatal Mental Health Project in South Africa. PLOS Medicine 9(5): e1001222. doi:10.1371/journal.pmed.1001222

15. Khalifeh H, Brauer R, Toulmin H, Howard LM (2015) Perinatal mental health: What every neonatologist should know. Early Hum Dev 91:649-653. doi:10.1016/j.earlhumdev.2015.08.010

16. Kingdon GG, Knight J (2004) Unemployment in South Africa: The Nature of the Beast. World Development 32:391-408. doi:10.1016/j.worlddev.2003.10.005

17. Lesch E, Adams AR (2016) Couples living with and around alcohol abuse: A study of a farmworker community in the Cape Winelands, South Africa. Social Science \& Medicine 156:167-174. doi: 10.1016/j.socscimed.2016.03.030 
18. Lorenzoni L, Roubal T (2016) “International Comparison of South African Private Hospital Price Levels”. OECD Health Working Papers, No. 85. OECD Publishing: Paris. doi:org/ 10.1787/5jrrxrzn24wl-en

19. Lückhoff M, Koen L, Jordaan E, Niehaus DJ (2014) Attempted suicide in a Xhosa schizophrenia and schizoaffective disorder population. Suicide Life Threat Behav 44(2):167-174. doi:10.1111/stlb.12066

20. Özkan IA, Mete S (2010) Pregnancy planning and antenatal health behaviour: findings from one maternity unit in Turkey. Midwifery 26(3):338-347. doi:10.1016/j.midw.2008.07.005

21. Paschetta E, Berrisford G, Coccia F, Whitmore J, Wood AG, Pretlove S, Ismail KMK (2014) Perinatal psychiatric disorders: an overview. AJOG 210:501-509. doi:10.1016/j.ajog.2013.10.009

22. Perinatal Task Team of the Western Cape Department of Health (2016) First 1000 days rapid situational analysis for the Western Cape December 2016. Western Cape Government: Cape Town.

23. Rochat TJ, Tomlinson M, Bärnighausen T, Newell M-L, Stein A (2011) The prevalence and clinical presentation of antenatal depression in rural South Africa. J Affect Disord 135:362-373. doi:10.1016/ j.jad.2011.08.011

24. Salisbury T (2015) Education and inequality in South-Africa: Returns to schooling in post-apartheid era. International Journal of Educational Development 46:43-52. doi:10.1016/j.ijedudev.2015.07.004

25. Shisana O, et al. (2014) South Africa national HIV prevalence, incidence and behaviour survey, 2012. Cape Town: HSRC Press.

26. Wang Y-G et al. (2017) Family history of suicide and high motor impulsivity distinguish suicide attempters from suicide ideators among college students. Journal of Psychiatric Research 90:21-25. doi:10.1016/j.jpsychires.2017.02.006 
27. Wellings K, et al. (2013) The prevalence of unplanned pregnancy and associated factors in Britain: fi ndings from the third National Survey of Sexual Attitudes and Lifestyles (Natsal-3). Lancet 382:1807-1816. doi:10.1016/ S0140-6736(13)62071-1

28. Williams PP, Jordaan E, Mathews C, Lombard C, Parry CDH (2014) Alcohol and other drug use during pregnancy among women attending midwife obstetric units in the Cape Metropole, South Africa. Advances in Preventative Medicine 2014:1-10. doi: 10.1155/2014/871427 
Table 1: Socio-demographic and psychiatric variables within study sample $(n=214)$

Total

Age (in years)

\begin{tabular}{lrr}
\hline $18-34$ & 148 & 69.2 \\
$35-46$ & 66 & 30.8 \\
Ethnicity & \\
\hline
\end{tabular}

\begin{tabular}{|c|c|c|}
\hline Caucasian & 84 & 39.3 \\
\hline Colored & 104 & 48.6 \\
\hline Other & 25 & 11.7 \\
\hline Unknown* & 1 & 0.5 \\
\hline \multicolumn{3}{|l|}{ Level of education } \\
\hline Lower than secondary school & 17 & 7.9 \\
\hline Secondary school & 122 & 57.0 \\
\hline Tertiary education & 71 & 33.2 \\
\hline Unknown* & 4 & 1.9 \\
\hline \multicolumn{3}{|l|}{ Marital status } \\
\hline Married & 117 & 54.7 \\
\hline Unmarried & 97 & 45.3 \\
\hline \multicolumn{3}{|l|}{ Employment status } \\
\hline Employed & 93 & 43.5 \\
\hline Unemployed & 118 & 55.1 \\
\hline Unknown* & 3 & 1.4 \\
\hline \multicolumn{3}{|c|}{ Monthly ousehold income (ZAR) } \\
\hline$<\mathrm{R} 4166(\$ 300)$ & 91 & 42.5 \\
\hline R4166-R8333 & 99 & 46.3 \\
\hline Missing values* & 24 & 11.2 \\
\hline \multicolumn{3}{|l|}{ Children } \\
\hline Yes & 128 & 60.0 \\
\hline No & 85 & 39.7 \\
\hline Unknown* & 1 & 0.5 \\
\hline
\end{tabular}


Gestation (weeks)

0-12

89

41.6

13-19

123

57.5

Unknown*

2

0.9

\section{Gravida}

\begin{tabular}{lrr}
\hline 1 & 57 & 26.6 \\
2 & 62 & 29.0 \\
3 & 44 & 20.6 \\
4 or more & 50 & 23.4 \\
Unknown* & 1 & 0.5 \\
Termination of pregnancy & 176 & 82.2 \\
\hline None & & 15.4 \\
1 or more & 33 & 2.3 \\
Unknown* & 5 & 5
\end{tabular}

Substance use

Yes

No

$162 \quad 75.7$

Unknown*

4

Previous psychiatric admissions

\begin{tabular}{lrr}
\hline Yes & 106 & 49.5 \\
No & 106 & 49.5 \\
Unknown* & 2 & 0.9 \\
Number of past suicide attempts & 139 & 65.0 \\
\hline 0 & 42 & 19.6 \\
1 & 32 & 15.0 \\
2 or more & 1 & 0.5 \\
Unknown* & 42 \\
Psychiatric diagnosis** & 115 & 53.6 \\
\hline Major depressive disorder & & 21.9 \\
Bipolar mood disorders & 47 & \\
\hline
\end{tabular}


Schizophrenia spectrum disorders

Total $\%$

Anxiety disorders

Other

* Unknown values exist due to cases where participants were unable or unwilling to provide certain information.

** The total number of psychiatric diagnoses adds up to more than the total number of study participants $(n=214)$ due to the inclusion of comorbid diagnoses. 
Table 2: Univariate models: The frequency (\%) and Relative Risk for unplanned pregnancy by sociodemographic and psychiatric characteristics

\begin{tabular}{|c|c|c|c|c|c|c|c|c|}
\hline & \multicolumn{2}{|c|}{ Total } & \multicolumn{2}{|c|}{$\begin{array}{l}\text { Unplanned } \\
\text { pregnancy }\end{array}$} & \multirow{2}{*}{$\mathbf{R R}$} & \multicolumn{2}{|c|}{$95 \% \mathrm{CI}$} & \multirow{2}{*}{$\mathbf{p}$} \\
\hline & $\mathbf{n}$ & $\%$ & $\mathbf{n}$ & $\%$ & & & & \\
\hline \multicolumn{9}{|c|}{ Maternal age (years) } \\
\hline $18-34$ & 148 & 69.2 & 78 & 52.7 & 1.5 & 1.0 & 2.2 & 0.027 \\
\hline $35-46$ & 66 & 30.8 & 23 & 34.8 & 1.0 & & & \\
\hline \multicolumn{9}{|c|}{ Maternal age at first child (years) } \\
\hline $13-24$ & 91 & 43.5 & 66 & 72.5 & 2.5 & 1.8 & 3.4 & 0.0001 \\
\hline $25-46$ & 118 & 56.5 & 34 & 28.8 & 1.0 & & & \\
\hline \multicolumn{9}{|l|}{ Gravida } \\
\hline 1 & 57 & 26.8 & 25 & 43.9 & 1.0 & & & \\
\hline 2 & 62 & 29.1 & 17 & 27.4 & 0.6 & 0.4 & 1.0 & 0.067 \\
\hline$>2$ & 94 & 44.1 & 58 & 61.7 & 1.4 & 1.0 & 2.0 & 0.047 \\
\hline \multicolumn{9}{|c|}{ Previous termination of pregnancy } \\
\hline None & 176 & 84.2 & 79 & 44.9 & 1.0 & & & \\
\hline One or more & 33 & 15.8 & 19 & 57.6 & 1.3 & 0.9 & 1.8 & 0.147 \\
\hline \multicolumn{9}{|l|}{ Etnicity } \\
\hline Caucasian & 84 & 74.3 & 14 & 16.7 & 1.0 & & & \\
\hline Colored & 104 & 92.0 & 74 & 71.2 & 4.3 & 2.6 & 7.0 & 0.0001 \\
\hline Other & 25 & 22.1 & 12 & 48.0 & 2.9 & 1.5 & 5.4 & 0.001 \\
\hline \multicolumn{9}{|c|}{ Marital status } \\
\hline Married & 117 & 54.7 & 30 & 25.6 & 1.0 & & & \\
\hline Unmarried & 97 & 45.3 & 71 & 73.2 & 2.9 & 2.0 & 4.0 & 0.0001 \\
\hline
\end{tabular}




\begin{tabular}{|c|c|c|c|c|c|c|c|c|}
\hline & \multicolumn{2}{|c|}{ Total } & \multicolumn{2}{|c|}{$\begin{array}{l}\text { Unplanned } \\
\text { pregnancy }\end{array}$} & \multirow{2}{*}{$\mathbf{R R}$} & \multicolumn{2}{|c|}{$95 \% \mathrm{CI}$} & \multirow{2}{*}{$\mathbf{p}$} \\
\hline & $\mathbf{n}$ & $\%$ & $\mathbf{n}$ & $\%$ & & & & \\
\hline \multicolumn{9}{|l|}{ Education } \\
\hline $\begin{array}{l}\text { Below secondary } \\
\text { school }\end{array}$ & 17 & 8.1 & 14 & 82.4 & 7.3 & 3.7 & 14.6 & 0.0001 \\
\hline Secondary school & 122 & 58.1 & 78 & 63.9 & 5.7 & 2.9 & 11.1 & 0.0001 \\
\hline Tertiary education & 71 & 33.8 & 8 & 11.3 & 1.0 & & & \\
\hline \multicolumn{9}{|l|}{ Employment status } \\
\hline Employed & 93 & 44.1 & 25 & 26.9 & 1.0 & & & \\
\hline Unemployed & 118 & 55.9 & 76 & 64.4 & 2.4 & 1.7 & 3.4 & 0.0001 \\
\hline \multicolumn{9}{|c|}{ Monthly household income (ZAR) } \\
\hline Less than R4166 & 91 & 47.9 & 50 & 54.9 & 1.6 & 1.2 & 2.3 & 0.004 \\
\hline More than R4166 & 99 & 52.1 & 33 & 33.3 & 1.0 & & & \\
\hline \multicolumn{9}{|c|}{ Substance use (alcohol, amphetamine, cannabis) } \\
\hline No & 162 & 77.1 & 65 & 40.1 & 1.0 & & & \\
\hline Yes & 48 & 22.9 & 34 & 70.8 & 1.8 & 1.4 & 2.3 & 0.0001 \\
\hline \multicolumn{9}{|c|}{ Number of past suicide attempts } \\
\hline 0 & 139 & 65.3 & 52 & 37.4 & 1.0 & & & \\
\hline 1 & 42 & 19.7 & 24 & 57.1 & 1.5 & 1.1 & 2.1 & 0.015 \\
\hline 2 or more & 32 & 15.0 & 25 & 78.1 & 2.1 & 1.6 & 2.8 & 0.0001 \\
\hline \multicolumn{9}{|c|}{ Previous psychiatric admissions } \\
\hline No & 106 & 50.0 & 36 & 34.0 & 1.0 & & & \\
\hline Yes & 106 & 50.0 & 64 & 60.4 & 1.8 & 1.3 & 2.4 & 0.0003 \\
\hline
\end{tabular}


Table 3: Independent risk factors for unplanned pregnancy: relative risk $(95 \% \mathrm{CI})$

\begin{tabular}{|c|c|c|c|}
\hline & $\mathbf{R R}$ & $95 \% \mathrm{CI}$ & $\mathbf{p}$ \\
\hline \multicolumn{4}{|l|}{ Marital status } \\
\hline Unmarried & 1.44 & 1.06 to 1.97 & 0.022 \\
\hline \multicolumn{4}{|l|}{ Level of education } \\
\hline Below secondary school & 3.69 & 1.68 to 8.07 & 0.001 \\
\hline Secondary school & 3.22 & 1.53 to 6.80 & 0.002 \\
\hline \multicolumn{4}{|l|}{ Ethnicity } \\
\hline Colored & 2.08 & 1.27 to 3.42 & 0.004 \\
\hline African/Indian & 1.51 & 0.84 to 2.73 & 0.171 \\
\hline \multicolumn{4}{|l|}{ Substance use } \\
\hline Yes & 1.27 & 1.04 to 1.56 & 0.022 \\
\hline \multicolumn{4}{|l|}{ Previous Suicide attempts } \\
\hline One & 1.16 & 0.89 to 1.51 & 0.285 \\
\hline Two or more & 1.42 & 1.11 to 1.82 & 0.006 \\
\hline
\end{tabular}

